\title{
COMPARISON OF PIXEL AND REGION-BASED APPROACHES FOR TREE SPECIES MAPPING IN ATLANTIC FOREST USING HYPERSPECTRAL IMAGES ACQUIRED BY UAV
}

\author{
G. T. Miyoshi ${ }^{1, *}$, N. N. Imai ${ }^{1,2}$, A. M. G. Tommaselli ${ }^{1,2}$, E. Honkavaara ${ }^{3}$ \\ ${ }^{1}$ Post Graduate Program in Cartographic Science, São Paulo State University (UNESP), Presidente Prudente-SP, Brazil - \\ takahashi.gabi@gmail.com \\ ${ }^{2}$ Dept. of Cartography, São Paulo State University (UNESP), Presidente Prudente-SP, Brazil - (nilton.imai, a.tommaselli)@ unesp.br \\ ${ }^{3}$ Finnish Geospatial Research Institute FGI, Geodeetinrinne 2, P.O. Box 15, FI-02431 Masala, Finland - eija.honkavaara@nls.fi
}

KEY WORDS: Image classification, Random Forest, Atlantic Forest, Hyperspectral images

\begin{abstract}
:
The objective of this work was the comparison of two different classification approaches to detect four different tree species of a highly diverse tropical Atlantic Forest area. In order to achieve the objective, images were acquired with the Rikola hyperspectral camera onboard the UX4 UAV. The study area is in the Western part of São Paulo State, a tropical Atlantic Forest area protected by governmental laws, which contains areas already deforested in the past and which are currently in regeneration. The tested approaches were one based only in the pixel values and other one based in regions. After the image acquisition, the images were radiometrically and geometrically processed. In addition, an airborne laser scanning point cloud was used to calculate the canopy height model of the area, which was used to detect the individual tree crowns with the superpixels method. Those superpixels were used to the region-based classification and to feature extraction. A total of 28 features were extracted where 25 correspond to the spectral bands acquired with the Rikola camera and three correspond to the three first principal components of the images. The features were extracted from the 91 samples recognized during a field work. From the total of samples, 19 were separated to validate the classification results. The chosen classifier was the Random Forests and the results presented a kappa coefficient of $18.20 \%$ and $36.57 \%$ for the pixel-based and region-based classifications showing that the second one had a better performance.
\end{abstract}

\section{INTRODUCTION}

Tree species recognition topic has been increased in the last years due to the forest importance and the development of different sensors and platforms to acquired Remote Sensing data (Fassnacht et al. 2016; Maschler, Atzberger, Immitzer, 2018). Knowledge of the tree species location can contribute to the sustainable management of forests, which has environmental and economic importance (Matsuki, Yokoya and Iwakasaki, 2015). Forests are not only habitat of thousands of different species, they play an important role in the carbon and water cycle and moreover, provide feedstock resources (PanequeGálvez et al., 2014; Romijn et al., 2015). In addition, mapping tree species allied with structural information can be a useful data to know the forest composition, with data about dominant species, biomass and successional stage of forest recovering.

Regarding the tree species mapping for forest inventories, they can be done using two mainly approaches: using data acquired in field or using remotely sensed data. The first one is not suitable, especially when the trees information are required over larger areas and the monitoring needs to repetitive (Immitzer, Atzberger, Koukal, 2012). Currently, with the miniaturized sensors and Unmanned Aerial Vehicles (UAVs) remotely information can be cheaper and faster acquired in comparison with the use of aircrafts or satellites especially if a higher temporal resolution is required. The use of UAVs can provide images with very high spatial resolution (VHSR), i.e., centimetres. When hyperspectral sensor is on-board of those platforms, besides the VHSR information, the spectral information can be acquired in a more detailed way, in dozens of spectral bands, sufficient to reconstruct the spectral signature of targets and being possible to show spectral differences not detected by multispectral data.

Classification approaches, among features and classifiers, are also important to tree species mapping in order to achieve better results. Nevalainen et al. (2017) applied five different classifiers in a region-based approach to identify four tree species in boreal forest in Finland. Different structural and spectral set of features were extract in a circular area around each tree centre to the classification. The best result was achieved with the Random Forests (RF) and Multilayer Perceptron classifiers, around 95\% of overall accuracy each.

Using the support vector machine (SVM) classifier, hyperspectral images and airborne laser scanner (ALS) data, Dalponte et al. (2014) classified three tree species of boreal forest from Norway. The authors verified different accuracies when using manual and automatically individual tree crowns (ITCs) where the best results were achieved with the manual ITCs. Another find of the authors were related with the selection of the training samples, being the spectral feature more influential than the information of the canopy height model (CHM).

Immitzer, Atzberger and Koukal (2012) compared pixel-based and object-based approaches of four tree species classification in temperate forest in Austria. The authors used WorldView-2 satellite images and the RF classifier concluding that the objectbased approach had a better performance than the pixel-based approach. Moreover, Ferreira et al. (2016) compared three different classifiers in hyperspectral and multispectral data from 
Brazilian tropical Atlantic Forest using a pixel-based approach. They also tested an object-oriented approach to the classification, achieving different accuracies. The best results were for the linear discriminant analysis, $90.10 \%$ of average accuracy, in the object-oriented approach.

It is worth noting, the importance of forest studies regarding the tree species classification. It is worth noting, the importance of forest studies regarding the tree species classification. Nonetheless, not only different approaches to identify tree species need to be studied, but need to be applied in different type of forests such as the Brazilian tropical Forests, which is still few studied according to Fassnacht et al. (2016). In this sense, the objective of this work is to test two different approaches to tree species classification of Brazilian Atlantic Forest, the pixel-based and region-based classifications one.

\subsection{Study area}

The study area is a Brazilian tropical Atlantic Forest fragment located in the Western part of São Paulo State, in Euclides da Cunha Paulista. It is a fragment protected by governmental law inside the Black-Lion Tamarin ecological station (ESEC-MLP). ESEC-MLP is composed by four different fragments, Santa Maria, Tucano, Água Sumida and Ponte Branca. The study area is inside Ponte Branca and has approximately $500 \mathrm{~m}$ by $130 \mathrm{~m}$ in length and width, respectively. Is a transitional area in terms of successional stages. The border of the area, which is closest to the road has smaller trees with an average height of $7.5 \mathrm{~m}$. The area further away from the road comprises trees up to approximately $20 \mathrm{~m}$ of height. According to data collected during field works conducted between 2015 and 2017, it was verified that the area comprises more than 20 different tree species with diameter at breast height bigger than $3.8 \mathrm{~cm}$ (Berveglieri et al., 2016; Miyoshi et al., 2018). Figure 1 shows images taken outside and inside the study area, presenting the heterogeneity of the area.
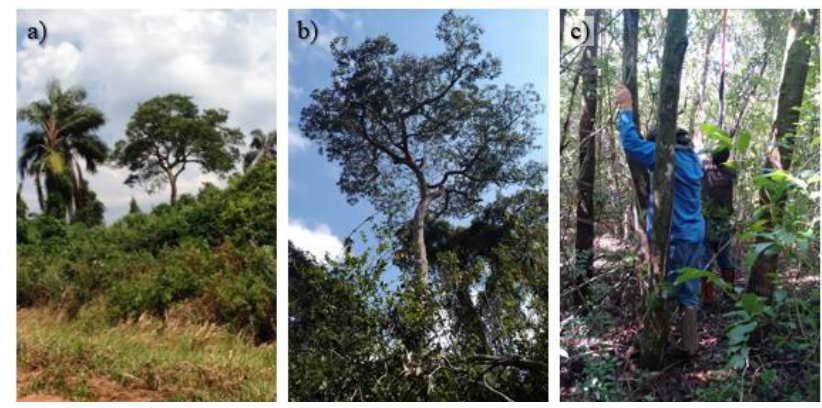

Figure 1. Images of the study area. a) Outside the area; b) c)

Inside the area

\section{METHODOLOGY}

The data processing included the following steps: i) Image acquisition; ii) Image processing (dark current and radiometric corrections as well as geometric processing and radiometric block adjustment); iii) Individual tree crown detection; iv) Features extraction; v) Tree species classification and evaluation.

\subsection{Image acquisition}

Using the UAV named UX4 developed by Nuvem UAV (http://nuvemuav.com/) specially to carry the Rikola hyperspectral camera, images were acquired in July $1^{\text {st }}$ of 2017. UX4 is a quadcopter controlled by PixHawk autopilot and able to fly until $30 \mathrm{~min}$ depending on weather, battery and payload conditions. Besides the Rikola camera, the payload is composed by a global navigation satellite system (GNSS) to record the position of the UAV and one RGB camera (GoPro Hero 4 Black). Figure 2 shows the UX4 UAV during a field campaign with the Rikola camera attached. The flight mission was realized from $10 \mathrm{~h} 14$ to $10 \mathrm{~h} 24$, local time (UTC-3) with the UAV speed of $4 \mathrm{~m} / \mathrm{s}$, providing images with forward overlap higher than $70 \%$.

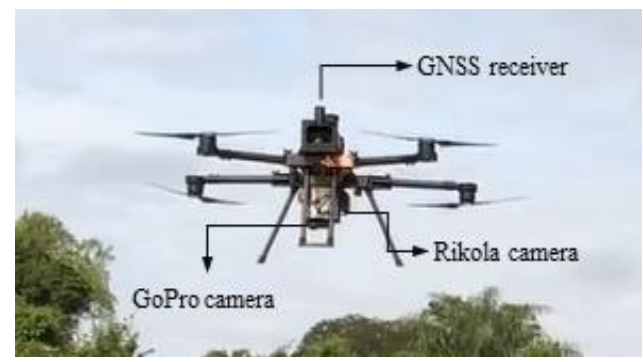

Figure 2. UX4 UAV and its payload

Rikola camera is a hyperspectral frame camera based on the Fabry-Pérot Interferometer (FPI). It can acquire different set of spectral bands, due to the FPI, in the two CMOS sensors. It has an approximated focal length of $8.7 \mathrm{~mm}$ and the frame format sensors are sized of $1017 \times 648$ pixels with a pixel size of 5.5 $\mu \mathrm{m}$ (Rikola, 2015; Miyoshi et al., 2018). 25 spectral bands distributed in the range between $500 \mathrm{~nm}$ and $900 \mathrm{~nm}$ were acquired as shown in Table 1 .

Central wavelengths of each spectral band (nm): 506.22, 519.94, $535.09,550.39,565.10,580.16,591.90,609.00,620.22,628.73$, $650.96,659.72,669.75,679.84,690.28,700.28,710.06,720.17$, $729.57,740.42,750.16,769.89,780.49,790.30,819.66$

FWHM (nm): $12.44,17.38,16.84,16.53,17.26,15.95,16.61$, $15.08,16.26,15.30,14.44,16.83,19.80,20.45,18.87,18.94,19.70$, $19.31,19.01,17.98,17.97,18.72,17.36,17.39,17.84$

Table 1. Spectral settings of the hyperspectral camera

\subsection{Image processing}

After image acquisition, the first step was performing the dark current and radiometric correction. Both processes were realized in the Hyperspectral imager software provide by the manufacturer. The dark current process uses a dark image acquired before the flight campaign, where the camera lens is covered with a dark object of low reflectance. In our flight campaign we used a synthetical material with average and constant reflectance of $4 \%$. The radiometric correction uses a file provided by the manufacturer, which is created based on their laboratory measures. After the radiometric correction, the images are represented in radiance values.

The geometrical process aims to calculate the camera calibration parameters from both sensors, e.g., focal length and distortions, and the exterior orientation parameter (EOP) of each image. Camera calibration used the geometrical self- 
calibration method. Aerial triangulation was performed in order to calculate the EOPs. Initial position of each image of spectral bands centered in $535.09 \mathrm{~nm}, 609 \mathrm{~nm}, 679.84 \mathrm{~nm}$ and 769.89 nm were used and refined with the Bundle Block Adjustment. Those bands were used because two are in the first CMOS sensor and the other two are in the second CMOS sensor. This processing was applied in the Agisoft PhotoScan software, which is based on Structure from Motion techniques. In addition, a digital surface model (DSM) of the area was calculated with a spatial resolution of $10 \mathrm{~cm}$, which was used in the radiometric block adjustment task. Regarding the remaining 21 spectral bands, which had not their EOP calculated during the aerial triangulation process, it is noticed that they were calculated using the methodology proposed by Honkavaara et al. $(2013 ; 2017)$.

Radiometric block adjustment was applied due to illumination differences among images. Possible cause of differences is the UAV movement, different cloud covering in the imaged area, forest structure and influences of the bidirectional reflectance distribution function (BRDF). The method applied was the one from Honkavaara et al. (2013) and uses the Sun zenithal and azimuthal angles and common points between overlapping images. In order to perform this task, the $\operatorname{radBA}$ software developed by Honkavaara et al. $(2013 ; 2017)$ at Finnish Geospatial Research Institute (FGI) was used.

Finally, a hyperspectral radiance orthophoto mosaic was calculated with a ground sample distance of $10 \mathrm{~cm}$, the same resolution as the DSM generated. In sequence, using three radiometric reference targets located in the area, the empirical line method (Smith and Milton, 1999) was applied to transform the pixels of the mosaic in reflectance factor values.

\subsection{Individual tree crown detection}

To perform the classification using the region-based approach, the ITC detection was necessary. Previous studies showed that the use of CHM provided could be used in this task (Nevalainen et al., 2017; Näsi et al., 2015). In this sense, using an airborne laser scanner data provided by Fototerra company (http://www.fototerra.com.br/ingles/) the CHM was calculated. Full wave form laser data was provided with point cloud density of 7.55 points $/ \mathrm{m}^{2}$. Using the LAStools package (Isenburg, 2014) the digital terrain model (DTM) was extracted. Moreover, the highest points of the point cloud were extracted to compose the DSM and then, subtracting the DTM from those data, a point cloud representing the $\mathrm{CHM}$ of the area was calculated

The method used to separate the ITC was the superpixels using the simple linear iterative clustering (SLIC) algorithm from Achanta et al. (2012). With initial parameter of 20,000 superpixel, segments were generated. This parameter was chosen due to the diversity of the area, with smaller and bigger tree crowns. Considering this, to avoid oversegmentation of tree crowns, where a single tree is represented in more than one superpixel, manual editing of the was needed. Figure 3 shows an example of the final superpixels of the area. It is important noting that, the ITC delineation was just visually evaluated based on the tree species recognized in field, as explained in the next section.

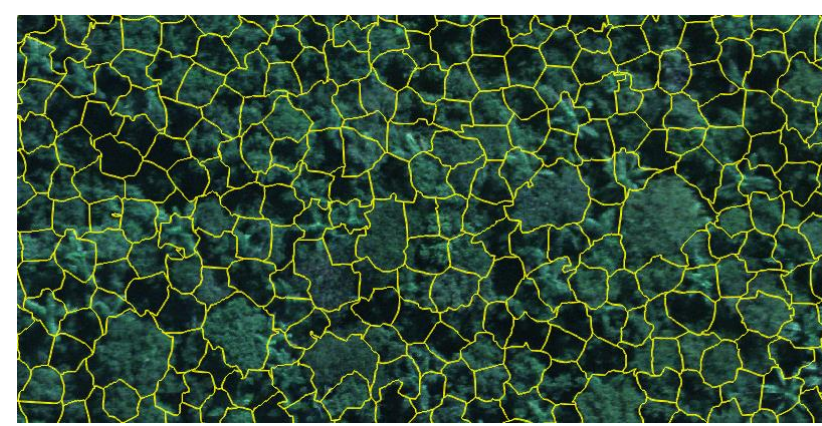

Figure 3. Final superpixels representing the individual tree crowns

\subsection{Tree species classification}

Two tree species classification were performed. Both were performed with the RF classifier from Breiman (2001), which uses multiple decision trees and the most popular vote as criteria to the classification.

Using tree species identification and localization acquired during field works realized in 2017 the training and validation samples were defined. From the 13 tree species recognized, only the four with greatest number of samples were used to avoid mistakes which might be caused due to unbalanced number of samples. Table 2 shows the tree species classified in this study and their total number of trees samples, while Figure 4 shows a spectral profile acquired of each specie.

\begin{tabular}{|c|c|c|}
\hline Specie & $\begin{array}{c}\text { Popular } \\
\text { name }\end{array}$ & $\begin{array}{c}\text { Number of tree species } \\
\text { recognized in field }\end{array}$ \\
\hline Copaifera langsdorffii & Copaiba & 25 \\
Apuleia leiocarpa & Garapa & 18 \\
Hymenaea courbaril & Jatobá & 14 \\
Syagrus romanzoffiana & Jerivá & 34 \\
\hline
\end{tabular}

Table 2. Tree species classified and their number of samples recognized in field

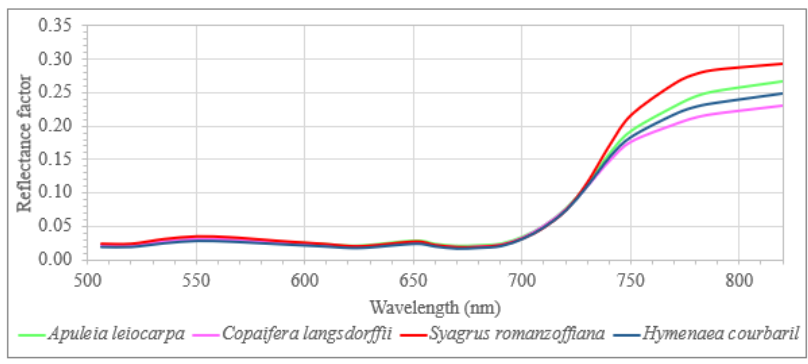

Figure 4. Sample spectra of each tree used to the classification

Tree species were associated to the superpixels using their position acquired in field. In sequence, $80 \%$ of the samples were randomly separated to train the classifier while, $20 \%$ were separated to validate the results. Regarding the features used, they were 28 , where 25 corresponds to the spectral bands acquired and three to the three first principal components (PC) of the mosaic of hyperspectral images. The PC were extracted using the ENVI software and the number of PC were chosen because they represented more than $95 \%$ of data variance. 
The features of region-based classification were calculated using the average value of each spectral band and PC in each superpixel. The features of the pixel-based classification were the nominal value of each pixel. RF classifier was applied in WEKA software using the training samples to build the model with the 10 -fold cross validation. As parameter of the RF it is highlighted the value 100 , which were the number of decision trees and number of interactions. Lastly, the classifications were evaluated using the remaining samples, the $20 \%$ samples. The statistics used to evaluate the results were the Cohen Kappa coefficient, user and producer accuracies, as well as the F-Score (Congalton, 1991; Li et al., 2012; Cohen, 1960)

\section{RESULTS}

The following sections show the results of each classification approach.

\subsection{Pixel-based classification.}

Based on the 190,418 pixels used as training sample, the model built using the 10-fold cross validation presented a kappa coefficient of $38.43 \%$ and number of correctly classified instances of $54.91 \%$. User and producer accuracies varied from $44.30 \%$ to $72.70 \%$ and from $34.60 \%$ to $72 \%$, respectively, being the highest values to Hymenaea courbaril. F-Score varied from $39.50 \%$ to $72.30 \%$, where the lowest value was to Apuleia leiocarpa and the highest was to Hymenaea courbaril. Table 3 presents the values resulting from the 10 -fold cross validation.

\begin{tabular}{|c|c|c|c|}
\hline Specie & User accur. & Producer accur. & F-Score \\
\hline $\begin{array}{c}\text { Copaifera } \\
\text { langsdorffii } \\
\text { Apuleia } \\
\text { leiocarpa }\end{array}$ & $44.30 \%$ & $37.20 \%$ & $40.40 \%$ \\
$\begin{array}{c}\text { Hymenaea } \\
\text { courbaril } \\
\text { Syagrus } \\
\text { romanzoffiana }\end{array}$ & $53.90 \%$ & $34.60 \%$ & $39.50 \%$ \\
\hline
\end{tabular}

Table 3. Result of the 10-fold cross validation model of the RF in the pixel-based approach classification

Applying this model in the validation set, the results were worst, with a kappa coefficient of $18.10 \%$ and most part of instances incorrectly classified, $61.54 \%$ against $38.46 \%$. Apuleia leiocarpa presented the lowest user and producer accuracies, $23.90 \%$ and $14.70 \%$, respectively, as well the lowest F-Score value, $18.20 \%$. The best results were achieved to Hymenaea courbaril with $66.1 \%$ of user accuracy, $64.40 \%$ of producer accuracy and $65.20 \%$ of F-Score. Table 4 and 5 shows the results for the validation test as well as the confusion matrix of the validation data.

\begin{tabular}{|c|c|c|c|}
\hline Specie & User ac. (\%) & Producer ac. (\%) & F-Score \\
\hline Copaifera & $46.50 \%$ & $25.60 \%$ & $33.10 \%$ \\
langsdorffii & $23.90 \%$ & $14.70 \%$ & $18.20 \%$ \\
Apuleia leiocarpa & $30.50 \%$ & $63.70 \%$ & $41.20 \%$ \\
$\begin{array}{c}\text { Hymenaea courbaril } \\
\text { Syagrus } \\
\text { romanzoffiana }\end{array}$ & $66.10 \%$ & $64.40 \%$ & $65.20 \%$ \\
\hline Kappa coefficient & \multicolumn{3}{|c|}{$18.10 \%$} \\
\hline
\end{tabular}

Table 4. Results of the validation set when RF model is applied in the pixel-based approach classification

\begin{tabular}{|c|c|c|c|c|}
\hline classified as $\rightarrow$ & $\mathrm{a}$ & $\mathrm{b}$ & $\mathrm{c}$ & $\mathrm{d}$ \\
\hline $\begin{array}{c}\mathrm{a}=\text { Copaifera } \\
\text { langsdorffii } \\
\begin{array}{c}\mathrm{b}=\text { Apuleia } \\
\text { leiocarpa }\end{array}\end{array}$ & 6593 & 4211 & 12669 & 2250 \\
$\begin{array}{c}\text { c = Hymenaea } \\
\text { courbaril } \\
\mathrm{d}=\text { Syagrus } \\
\text { romanzoffiana }\end{array}$ & 3154 & 2548 & 11011 & 1070 \\
\hline
\end{tabular}

Table 5. Confusion matrix of the validation set when RF model is applied in the pixel-based approach classification

\subsection{Region-based classification.}

Region-based model of RF used a lower number of samples because considered the average response of each superpixel and feature. The 10-fold cross validation resulted in a model with kappa coefficient of $36.57 \%$ and $54.79 \%$ of correctly classified instances against $45.21 \%$ of incorrectly classified instances. The lowest user and producer accuracies were obtained to Apuleia leiocarpa, with both values of $0 \%$. Highest values were $89.70 \%$ and $96.30 \%$ to Syagrus romanzoffiana, which also had the highest F-Score value, $92.90 \%$ (Table 6).

\begin{tabular}{|c|c|c|c|}
\hline Specie & User accur. & Producer accur. & F-Score \\
\hline $\begin{array}{c}\text { Copaifera } \\
\text { langsdorffii } \\
\text { Apuleia } \\
\text { leiocarpa }\end{array}$ & $41.70 \%$ & $47.60 \%$ & $44.40 \%$ \\
$\begin{array}{c}\text { Hymenaea } \\
\text { courbaril }\end{array}$ & $33.30 \%$ & $36.40 \%$ & $34.80 \%$ \\
$\begin{array}{c}\text { Syagrus } \\
\text { romanzoffiana }\end{array}$ & $89.70 \%$ & $96.30 \%$ & $92.90 \%$ \\
\hline
\end{tabular}

Table 6. Result of the 10-fold cross validation model of the RF in the region-based approach classification

Applying this model to the superpixels of the validation test, it was achieved a kappa coefficient of $33.72 \%$, higher than the one obtained for the pixel-based classification. The user and producer accuracies varied from $0 \%$ to $100 \%$, where the lowest values were to Apuleia leiocarpa and the highest were to Syagrus romanzoffiana. Table 7 shows the kappa coefficient value and the accuracy metrics for each specie, while Table 8 shows the resultant confusion matrix.

\begin{tabular}{|c|c|c|c|}
\hline Specie & User ac. (\%) & Producer ac. (\%) & F-Score \\
\hline Copaifera & $25.00 \%$ & $40.00 \%$ & $30.80 \%$ \\
langsdorffii & $00.00 \%$ & $00.00 \%$ & $00.00 \%$ \\
Apuleia leiocarpa & $50.00 \%$ & $33.30 \%$ & $40.00 \%$ \\
Hymenaea courbaril & $100.00 \%$ & $100.00 \%$ \\
$\begin{array}{c}\text { Syagrus } \\
\text { romanzoffiana }\end{array}$ & $100.00 \%$ & $33.72 \%$ \\
\hline Kappa coefficient & \multicolumn{3}{|c}{} \\
\hline
\end{tabular}

Table 7. Results of the validation set when RF model is applied in the region-based approach classification 


\begin{tabular}{|c|c|c|c|c|}
\hline classified as $\rightarrow$ & $\mathrm{a}$ & $\mathrm{b}$ & $\mathrm{c}$ & $\mathrm{d}$ \\
\hline $\begin{array}{c}\mathrm{a}=\text { Copaifera } \\
\text { langsdorffii } \\
\mathrm{b}=\text { Apuleia } \\
\begin{array}{c}\text { leiocarpa } \\
\mathrm{c}=\text { Hymenaea } \\
\text { courbaril }\end{array}\end{array}$ & 2 & 2 & 1 & 0 \\
$\begin{array}{c}\mathrm{d}=\text { Syagrus } \\
\text { romanzoffiana }\end{array}$ & 0 & 0 & 0 & 0 \\
\hline
\end{tabular}

Table 8. Confusion matrix of the validation set when RF model is applied in the region-based approach classification

\section{DISCUSSION AND CONCLUSION}

This study compared the pixel-based and the region-based classification of the same dataset. The hyperspectral images were acquired over a tropical Atlantic Forest area using the hyperspectral camera onboard UAV.

The results showed that the region-based approach performed better when compared to the pixel-based approach which was consistent to the existent literature even when applied in different type of forests (Féret and Asner, 2013; Clark and Roberts, 2012; Heinzel and Koch, 2012; Immitzer, Atzberger and Koukal, 2012).

Considering the region-based method, superpixels were used to the ITC detection and delineation. However, manual editing was needed in order to correct the oversegmentation of tree crowns. Regarding the classification results, it is noticed that Apuleia leiocarpa could not be identified by the classification model, presenting the worst results of classification, while all the validation samples of Syagrus romanzoffiana where correctly identified. Probable causes of these results are the spectral similarity between species as was possible to see in Figure 4. Syagrus romanzoffiana could presented better results because it has a different shape when compared with the other tree species, it is a palm tree which can be used to check the degree of regeneration of this forest, since it is one of the first species to grow after the deforestation.

Finally, notwithstanding the challenging dataset, where the spectral similarity of the tree species is high and the forest is dense, results were promising and enables possibilities to extract new features to be used in the region-based classification.

\section{ACKNOWLEDGEMENTS}

This research is ostensibly supported by the São Paulo Research Foundation (FAPESP - grant 2013/50426-4) and Academy of Finland - grant number 305994), as well the Conselho Nacional de Desenvolvimento Científico e Tecnológico (CNPq) (grant 153854/2016-2) and Coordenação de Aperfeiçoamento de Pessoal de Nível Superior (CAPES) (process 88881.187406/2018-01)

\section{REFERENCES}

Achanta, R., Shaji, A., Smith, K., Lucchi, A., Fua, P., Süsstrunk, S., 2012. SLIC superpixels compared to state-of-theart superpixel methods. IEEE transactions on pattern analysis and machine intelligence, 34(11),

$2274-2282$

doi.org/10.1109/TPAMI.2012.120

Berveglieri, A., Tommaselli, A. M. G., Imai, N. N., Ribeiro, E. A. W., Guimarães, R. B., Honkavaara, E., 2016. Identification of Successional Stages and Cover Changes of Tropical Forest Based on Digital Surface Model Analysis. IEEE Journal of Selected Topics in Applied Earth Observations and Remote Sensing, 9(12), 5385-5397. doi.org/10.1109/JSTARS. 2016.2606320

Breiman, L., 2001. Random forests. Machine learning, 45(1), 5-32. doi.org/10.1023/A:1010933404324.

Clark, M. L., Roberts, D. A., 2012. Species-level differences in hyperspectral metrics among tropical rainforest trees as determined by a tree-based classifier. Remote Sensing, 4(6), 1820-1855. doi.org/10.3390/rs4061820.

Cohen, J., 1960. A coefficient of agreement for nominal scales. Educational and psychological measurement, 20(1), 37-46. doi.org/10.1177/001316446002000104.

Congalton, R. G., 1991. A review of assessing the accuracy of classifications of remotely sensed data. Remote sensing of environment, 37(1), 35-46. doi.org/10.1016/00344257(91)90048-B.

Dalponte, M., Ørka, H. O., Ene, L. T., Gobakken, T., Næsset, E., 2014. Tree crown delineation and tree species classification in boreal forests using hyperspectral and ALS data. Remote sensing of environment, 140, 306-317. doi.org/10.1016/j.rse.2013.09.006.

Fassnacht, F. E., Latifi, H., Stereńczak, K., Modzelewska, A., Lefsky, M., Waser, L. T., Straub, C., Ghosh, A., 2016. Review of studies on tree species classification from remotely sensed data. Remote Sensing of Environment, 186, 64-87. doi.org/10.1016/j.rse.2016.08.013.

Féret, J. B., Asner, G. P., 2013. Tree species discrimination in tropical forests using airborne imaging spectroscopy. IEEE Transactions on Geoscience and Remote Sensing, 51(1), 73-84. doi.org/10.1109/TGRS.2012.2199323.

Ferreira, M. P., Zortea, M., Zanotta, D. C., Shimabukuro, Y. E., de Souza Filho, C. R. (2016). Mapping tree species in tropical seasonal semi-deciduous forests with hyperspectral and multispectral data. Remote Sensing of Environment, 179, 66-78. doi.org/10.1016/j.rse.2016.03.021

Heinzel, J., Koch, B., 2012. Investigating multiple data sources for tree species classification in temperate forest and use for single tree delineation. International Journal of Applied Earth Observation and Geoinformation, 18, 101-110. doi.org/10.1016/j.jag.2012.01.025.

Honkavaara, E., Rosnell, T., Oliveira, R., Tommaselli, A., 2017. Band registration of tuneable frame format hyperspectral UAV imagers in complex scenes. ISPRS Journal of Photogrammetry and Remote Sensing, 134, 96-109. doi.org/10.1016/j.isprsjprs.2017.10.014.

Honkavaara, E., Saari, H., Kaivosoja, J., Pölönen, I., Hakala, T., Litkey, P., Mäkynen, J., Pesonen, L., 2013. Processing and assessment of spectrometric, stereoscopic imagery collected 
using a lightweight UAV spectral camera for precision agriculture. Remote Sensing, 5(10), 5006-5039. doi.org/10.3390/rs5105006.

Immitzer, M., Atzberger, C., Koukal, T., 2012. Tree species classification with random forest using very high spatial resolution 8-band WorldView-2 satellite data. Remote Sensing, 4(9), 2661-2693. doi.org/10.3390/rs4092661.

Isenburg, M, 2014. LAStools - efficient LiDAR processing software (version 141017, unlicensed), obtained from http://rapidlasso.com/LAStools

Li, W., Guo, Q., Jakubowski, M. K., Kelly, M., 2012. A new method for segmenting individual trees from the lidar point cloud. Photogrammetric Engineering \& Remote Sensing, 78(1), 75-84. doi.org/10.14358/PERS.78.1.75.

Maschler, J., Atzberger, C., Immitzer, M., 2018. Individual Tree Crown Segmentation and Classification of 13 Tree Species Using Airborne Hyperspectral Data. Remote Sensing, 10(8), 1218. doi.org/10.3390/rs10081218.

Matsuki, T., Yokoya, N., Iwasaki, A., 2015. Hyperspectral tree species classification of Japanese complex mixed forest with the aid of LiDAR data. IEEE Journal of Selected Topics in Applied Earth Observations and Remote Sensing, 8(5), 2177-2187. doi.org/10.1109/JSTARS.2015.2417859

Miyoshi, G. T., Imai, N. N., Tommaselli, A. M. G., Honkavaara, E., 2018. Impact of reduction of radiometric resolution in hyperspectral images acquired over forest field. International Archives of the Photogrammetry, Remote Sensing \& Spatial Information Sciences. 301-305. doi.org/10.5194/isprs-archivesXLII-1-301-2018

Näsi, R., Honkavaara, E., Lyytikäinen-Saarenmaa, P., Blomqvist, M., Litkey, P., Hakala, T., Viljanen, N., Kantola, T., Tanhuanpää, T., Holopainen, M., 2015. Using UAV-based photogrammetry and hyperspectral imaging for mapping bark beetle damage at tree-level. Remote Sensing, 7(11), 1546715493. doi.org/10.3390/rs71115467.

Nevalainen, O., Honkavaara, E., Tuominen, S., Viljanen, N., Hakala, T., Yu, X., Hyyppä, J., Saari, H., Pölönen, I., Imai, N. N., Tommaselli, A. M., 2017. Individual tree detection and classification with UAV-based photogrammetric point clouds and hyperspectral imaging. Remote Sensing, 9(3), 185. doi.org/10.3390/rs9030185.

Paneque-Gálvez, J., McCall, M. K., Napoletano, B. M., Wich, S. A., Koh, L. P., 2014. Small drones for community-based forest monitoring: An assessment of their feasibility and potential in tropical areas. Forests, 5(6), 1481-1507. doi.org/10.3390/f50 61481 .

Rikola Ltd., 2015. Rikola Hyperspectral Imager - Quick start Guide. Kaitoväylä, Oulu, Finland.

Romijn, E., Lantican, C. B., Herold, M., Lindquist, E., Ochieng, R., Wijaya, A., Murdiyarso, L. V., Verchot, L., 2015. Assessing change in national forest monitoring capacities of 99 tropical countries. Forest Ecology and Management, 352, 109-123. doi.org/10.1016/j.foreco.2015.06.003.
Smith, G., Milton E., 1999. The use of the empirical line method to calibrate remotely sensed data to reflectance. International Journal of Remote Sensing, 20(13), 2653-2662. doi.org/10.1080/014311699211994. 